\title{
An in vitro study to evaluate and compare the remineralizing potential among Casein Phosphopeptide-amorphous Calcium Phosphate (CPP-ACP) with fluoride and surface pre-reacted glass (S-PRG) fillers using quantitative analysis
}

\author{
Shabista Jabi1, ${ }^{*}$, Swati Dwivedi², Vinod Upadhyay², Ahsan Abdullah ${ }^{3}$, Mohammad Sarfaraj ${ }^{4}$, \\ Ankur Mishra4 \\ ${ }^{1}$ Postgraduate Student, ${ }^{2}$ Professor, ${ }^{3}$ Reader, ${ }^{4}$ Senior Lecturer, Department of Pediatric and Preventive \\ Dentistry, Career Postgraduate Institute of Dental Sciences \& Hospital, Lucknow, India.
}

\section{$\begin{array}{lllllllllllllllllll}\text { I } & \text { N } & F & O & \text { R } & \text { M } & \text { A } & \text { T } & \text { I } & \text { O } & \text { N } & \text { A } & \text { B } & \text { S } & \text { T } & \text { R A A } & \text { C } & \text { T }\end{array}$}

\section{Article History}

Received 12 th March 2021

Received revised 23rd May 2021

Accepted $7^{\text {th }}$ June 2021

Available online

$1^{\text {st }}$ August 2021

\section{K E Y W O R D S}

Casein phosphopeptide amorphous calcium fluoride phosphate

Fluoride

Surface pre-reacted glass filler

White spot lesion

Teeth

Remineralization

Demineralization
Background: Early treatment of white spot lesions is essential to prevent the progression of the lesion.

Aim: To evaluate and compare the remineralizing potential of CPP-ACP with fluoride (Casein Phospho Peptide-Amorphous Calcium Phosphate) and S-PRG fillers (Surface Pre reacted glass fillers) using atomic absorption spectroscopy and colorimetric method.

Materials and methods: Forty sound human premolars were used in this study. They were divided into two groups (A \& B), consisting of 20 samples in each. White spot lesions (WSLs) were established on the window $\left(4 \times 4 \mathrm{~mm}^{2}\right)$ created on the buccal surfaces of the samples. Samples in group A were treated with casein phosphopeptide amorphous calcium phosphate (CPP-ACP) with fluoride, those of group B were treated with S-PRG Fillers. The sample teeth were immersed in a demineralizing solution for 4 days. All the samples were subjected to loss of mineral content (wt \%), i.e., calcium, using atomic absorption spectroscopy and phosphorus using the colorimetric method.

Results: Statistical analysis was performed using one-way analysis of variance, Tukey's and paired t-tests. Group A exhibited the highest remineralizing potential, followed by Group B. Statistically, a significant difference ( $p=0.001)$ was observed between the two groups.

Conclusion: There was a significant difference in remineralizing potential of CPP-ACP with fluoride and S-PRG Fillers. CPP-ACP with fluoride appears to be an effective technique in the remineralization of white spot lesions.

\section{Introduction}

Dental caries is one of the oldest diseases since mankind, and it is often described as a "pandemic" disease due to its high prevalence [1]. Signs of the caries process are the first molecular change in the apatite crystals of the tooth, to a visible white spot lesion (WSL), or even eventual cavitation. It occurs as a result of cyclic demineralization and remineralization of enamel due to altered $\mathrm{pH}$ levels. Demineralization is defined as the process by which minerals (calcium and phosphate ions) are removed from the tooth. Demineralization occurs at low

Correspondence: ${ }^{*}$ Corresponding author Email Address: jabi.shabs@gmail.com

How to cite this article: Jabi S, Dwivedi S, Upadhyay V, Abdullah A, Sarfaraj MD, Mishra A. An in vitro study to evaluate and compare the remineralizing potential among Casein Phosphopeptide-amorphous Calcium Phosphate (CPP-ACP) with fluoride and surface pre-reacted glass (S-PRG) fillers using quantitative analysis. Int J Dent Mater 2021;3(3): 70 - 75. DOI: http://dx.doi.org/10.37983/IJDM.2021.3301 
$\mathrm{pH}$ when the oral environment is saturated with mineral ions, compared to a tooth's mineral content. In contrast, remineralization of tooth enamel is defined as the process whereby calcium and phosphate ions are supplied from an external source to promote ion-deposition on demineralized enamel crystals to produce mineral gain [2].

WSLs occur due to the breaching of the enamel layer by the pathogenic bacteria. These bacteria produce organic acids, resulting in leaching out numerous amounts of calcium and phosphate ions. These ions may or may not be replaced naturally by the remineralisation process [3]. The White Spot Lesions (WSL) are usually formed in patients who have undergone fixed orthodontic treatment. Other factors include xerostomia, high caries index, fluorosis and developmental hypoplasia. The white spot is most easily observed when the enamel is thoroughly dried. Therefore, the treatment of such lesions should improve the aesthetics and prevention of caries progression [4].

The first line of management of white spot is remineralization. The development of white spot lesions can be slowed or even arrested by various procedures such as removal of etiologic factors like maintaining oral hygiene and use of remineralizing agents such as topical fluorides, CPP-ACP, Bioactive glass, ACP technology, Tri-calcium phosphate, Xylitol, Icon, SDF and S-PRG fillers [5].

Calcium phosphate remineralization technology based on CPP-ACP with fluoride (Mi Varnish) has been recently developed, where CPP stabilizes high calcium and phosphate ions concentrations, together with fluoride ions, at the tooth surface by adhering to pellicle and plaque, thus preventing demineralization and enhancing remineralization. In S-PRG filers, a prereacted glass-ionomer technology is used. This technology forms a stable glass-ionomer phase in fillers by a pre-reacting acid-reactive glass containing fluoride with polyacrylic acid in the presence of water [6].

There is a lack of information regarding comparison among these remineralizing agents. Hence, this invitro study was designed to evaluate the remineralizing potential of CPP-ACP with Fluoride and S-PRG fillers in extracted human permanent teeth using atomic absorption spectroscopy and colorimetric method.

\section{Materials and methods}

In the present in-vitro study sound premolars, indicated for orthodontic extractions were included in the study. The extracted teeth with caries, morphological variations, fractured crowns, fluorosis and hypoplastic lesions were excluded. A total of 40 sample teeth were collected. The soft tissue deposits and calculus were removed from the teeth with a surface scaler. The crowns were resected from the roots. Collected sample teeth were coated with nail varnish (Colorama nail varnish, Maybelline), leaving a $4 \times 4 \mathrm{~mm}^{2}$ window on the buccal surface. Then, the 40 teeth samples were divided into groups such as Group A and B, which comprises 20 teeth each. Each teeth sample was immersed in demineralizing solution (composed of $1050 \mathrm{ml}$ of distilled water, $2 \mathrm{~g}$ of calcium chloride, $2.2 \mathrm{~g}$ of potassium hydrogen orthophosphate, $3 \mathrm{~g}$ of acetic acid, $56 \mathrm{~g}$ of potassium hydroxide) for four days to create an artificial white spot lesion (Figure 1). The $\mathrm{pH}$ of the solution was maintained at 3.5.

After four days, the sample teeth were removed from the solution. On the artificially created white spot lesion of teeth samples, CPP-ACP with fluoride (GC, MI Varnish, India) was applied in Group A, and S-PRG Fillers (Shofu Inc., Kyoto, Japan) were applied in group B (Figures 2 and 3, respectively).

Post remineralizing solution application, the samples were immersed in the demineralizing solution for 4 days. Then, all the samples were tested for loss of mineral content (wt\%), i.e., of calcium using atomic absorption spectroscopy (AAS) and phosphorus using the colorimetric method. AAS was used to perform trace elemental analysis which is important for variety of reasons. AAS has high sensitivity, often exhibiting detection limits at parts per trillion level and high selectivity due to the presence of extremely narrow spectral line. The technique is capable of analysing for multiple elements simultaneously and can easily be automated. Concentrations of atoms are measured by absorption or emission of specific wavelengths of radiation. As the quantity of energy put in to flame is known, the quantity remaining at the outer end can be measured. Whereas, calorimetric techniques are useful in the analysis of a wide range of substances. There is often a direct relationship between the intensity of the colour of a solution and the concentration of the coloured component (the analyte species) which it contains. This direct relationship forms the basis of the 


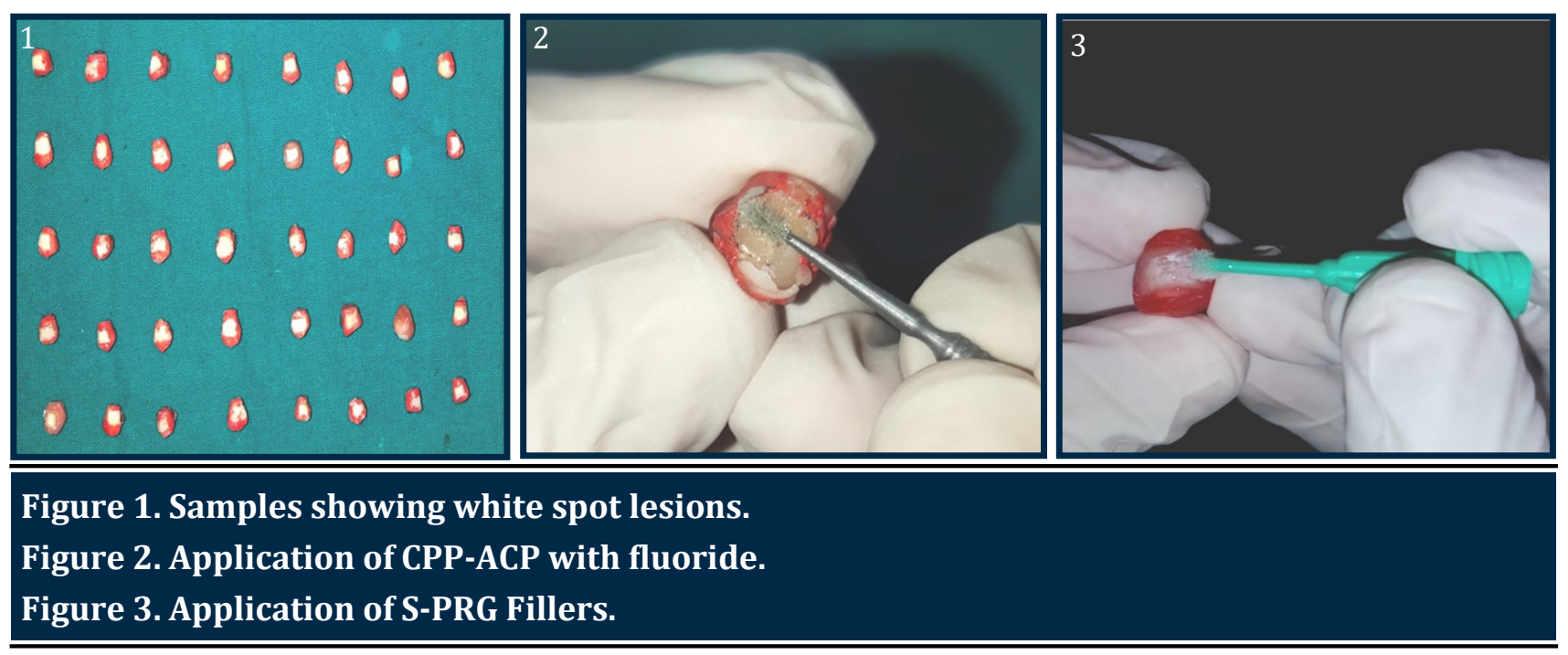

colorimetric technique. The loss of ions in groups $\mathrm{A}$ and $B$ were recorded in microgram/deciliter $(\mu \mathrm{g} / \mathrm{dl})$.

The obtained data were subjected to statistical analysis using SPSS software, Version 22.0, USA. Data were summarised as Mean \pm SE (standard error of the mean). Pre and post groups were compared by paired t-test. Pre- and post-change (pre-post) outcome measures of two groups were compared by one-factor analysis of variance (ANOVA). The significance of the mean difference between the groups was done by HSD (honestly significant difference) post hoc test after ascertaining normality by and homogeneity of variance between groups by a two-tailed $(\alpha=2)$ test and $p<0.05$ was considered as statistically significant.

\section{Results}

The obtained data of remineralization of calcium and phosphorous in both the groups are given in Tables 1 and 2 , respectively. Comparing $\mathrm{Ca}: \mathrm{P}$, the teeth applied with CPP-ACP with fluoride showed higher remineralization potential than those applied with S-PRG Fillers (Table 1 and 2, respectively). In addition, one-way ANOVA showed a significant difference $(p=0.001)$ between the groups in the remineralization of both Calcium and Phosphorous (Tables 1 and 2, respectively).

After treating with CPP-ACP with fluoride (Group A) and S-PRG fillers (Group B), the teeth showed a decrease in the mean Calcium and Phosphorous ion levels (tables 3 and 4). This decrease in Calcium and Phosphorus ion levels was higher or significant in Group A compared to Group B. (Tables 3 and 4).
Tukey t-test showed significantly different and higher remineralization in Calcium and Phosphorus of Group A compared to Group B (S-PRG Fillers). A decreased calcium and Phosphorus ions loss were observed after treating using CPP-ACP with fluoride, which showed a better demineralization preventing mechanism. This indicates increased remineralization potential of CPPACP with fluoride than S-PRG Fillers.

\section{Discussion}

Enamel white spot lesions are one of the common problems encountered by the dental practitioner and also a major esthetic concern [7]. The treatment of these white spot lesions should aim to assess the lesion progressions and improve the esthetics by eliminating the opacity [3]. Diminishing opacity caused by white spot lesion can be achieved by various noninvasive approaches, including the use of remineralizing agents. In this regard, fluoride varnishes have been the standard of practice for the professional application of fluoride [8]. Arends and Tencate (1981) [9] observed that salivary remineralization of enamel by topical fluoride had been shown to give rise to predominantly surface remineralization. Thus, achieving substantial remineralization of enamel is a big challenge.

The retention of fluoride on enamel and subsurface lesion remineralization depends on the availability of calcium and phosphate ions, and combining calcium, phosphate and fluoride ions can lead to loss of bioavailable fluoride ions. To overcome this incompatibility, recently, the combination of CPP-ACP with fluoride have been introduced as dental varnish (Mi Varnish) [10]. Kariya et al. (2004) [11] demonstrated 


\section{Table 1. Remineralization of calcium ( $\mu \mathrm{g} / \mathrm{dl}$ ) of two groups (ANOVA)}

\begin{tabular}{lccc}
\hline Groups & $\begin{array}{c}\text { Remineralization } \\
\text { (Mean } \pm \text { Standard Error) }\end{array}$ & F-value & $\begin{array}{c}\text { Significance } \\
\text { (p-value) }\end{array}$ \\
\cline { 1 - 2 } Group A (CPP-ACP) & $2.14 \pm 0.29$ & 12.25 & 0.001 \\
\cline { 1 - 2 } Group B (S-PRG) & $1.81 \pm 0.37$ & & \\
\hline
\end{tabular}

\begin{tabular}{lccc}
\hline Table 2. Remineralization of phosphorus $(\boldsymbol{\mu g} / \mathbf{d l})$ of two groups (ANOVA) & \\
\hline Groups & $\begin{array}{c}\text { Remineralization } \\
\text { (Mean } \pm \text { Standard Error) }\end{array}$ & F-value & $\begin{array}{c}\text { Significance } \\
\text { (p-value) }\end{array}$ \\
\hline Group A (CPP-ACP) & $1.73 \pm 0.13$ & 26.59 & 0.001 \\
\hline Group B (S-PRG) & $1.17 \pm 0.12$ & & \\
\hline
\end{tabular}

Table 3. Pre-test and post-test calcium ion levels (Mean \pm Standard Error) of two groups

\begin{tabular}{cccccc}
\hline \hline Groups & $\begin{array}{c}\text { Pre-test } \\
(\mathbf{n = 2 0 )}\end{array}$ & $\begin{array}{c}\text { Post-test } \\
(\mathbf{n = 2 0 )}\end{array}$ & $\begin{array}{c}\text { Mean change } \\
\text { (Pre-Post) }\end{array}$ & t-value & $\begin{array}{c}\text { Significance } \\
\text { (p-value) }\end{array}$ \\
\hline Group A & $45.07 \pm 0.73$ & $42.93 \pm 0.72$ & $2.14 \pm 0.29$ & 7.28 & 0.001 \\
\hline Group B & $46.78 \pm 0.58$ & $44.98 \pm 0.55$ & $1.81 \pm 0.37$ & 4.82 & 0.001 \\
\hline
\end{tabular}

\begin{tabular}{cccccc}
\hline Table 3. Pre-test and post-test phosphorus $(\boldsymbol{\mu g} / \mathbf{d l})$ & of two groups & (Mean \pm Standard Error). \\
\hline Group & $\begin{array}{c}\text { Pre-test } \\
(\mathbf{n = 2 0})\end{array}$ & $\begin{array}{c}\text { Post-test } \\
(\mathbf{n = 2 0})\end{array}$ & $\begin{array}{c}\text { Mean change } \\
\text { (Pre-Post) }\end{array}$ & t-value & $\begin{array}{c}\text { Significance } \\
\text { (p-value) }\end{array}$ \\
\hline Group A & $41.71 \pm 0.62$ & $39.98 \pm 0.59$ & $1.73 \pm 0.13$ & 13.21 & 0.001 \\
\hline Group B & $40.49 \pm 0.59$ & $39.33 \pm 0.56$ & $1.17 \pm 0.12$ & 9.75 & 0.001 \\
\hline
\end{tabular}

the improved acid-resistant effect of enamel by applying fluoride added CPP-ACP [11]. Studies affirmed that although the application of CPP-ACP often achieves the remineralization of superficial white spot lesions, this technique showed unsatisfactory results with respect to old and/ or deep lesions as well as to obtain aesthetics [10].

Newly introduced material S-PRG Fillers offers a more conservative approach. These S-PRG Fillers have the ability to release and recharge fluoride ions, and then they can achieve sustained fluoride release, which is acidity dependent. It releases ions like $\mathrm{Sr}, \mathrm{B}, \mathrm{Na}$ and $\mathrm{F}$ when it comes in contact with water or acidic solution [12].

Hence, the present study was conducted to evaluate the remineralizing potential of CPP-ACP with fluoride and S-PRG Fillers. The $\mathrm{pH}$ cycling protocol followed in the present study was as described by Babu et al. (2018) [8] because this model stimulates the in-vivo caries risk condition. The cycle of demineralization and remineralization was completed by immersing the sample teeth in the demineralizing solution, followed by applying the remineralizing agent. In the present study, the loss of ions was estimated by AAS and colorimetric method [13]. As observed in the current study, Ali A Assiry (2019) [13] has shown the loss of calcium and phosphorus ions on immersing in a demineralizing solution.

In the present study, the two remineralising agents were able to remineralise the white spot lesions. The teeth specimens treated with CPP-ACP with fluoride (Group A) showed the highest remineralising potential compared to the teeth treated with S-PRG Fillers (Group B). In tandem with the current study, Wokamatsu et al. (2018) [12] concluded that the application of PRG coat to WSLs is a more conservative approach. PRG barrier acts as an adjunct to a periodic fluoride application, promoting a beneficial remineralisation effect on WSLs [12].

Higher fluoride concentrations can cause rapid mineral 
precipitation on the enamel surface and obturation of the surface enamel pores that connect with the underlying demineralised lesion. Anticariogenic potential of CPP has been attributed to the ability of CPP to localise ACP at the tooth surface. CPP maintains supersaturation of calcium and phosphate ions, thus modulating the bioavailability of calcium phosphate levels and finally leading to an increase in remineralisation. Thus, CPP-ACP has shown to reduce demineralisation and enhance remineralisation of the enamel subsurface carious lesions. CPP-ACP has a remineralising effect on artificial subsurface enamel lesions and the remineralisation effect increased with an increase in the usage of the paste on the $1^{\text {st }}, 5^{\text {th }}$ and $10^{\text {th }}$ day, respectively. This could be the reason for the highest level of remineralisation in the sample of Group A (CPP-ACP) with fluoride [14].

The ability to release and recharge fluoride ions is acidity dependent, and under external force, these carious lesions treated by S-PRG Fillers may collapse and lead to cavitation $[15,16]$. This could be the reason for the low level of remineralisation in the samples treated with S-PRG Fillers.

The present study found out that the mean Calcium and Phosphorus ions level decreased after the treatment. The decrease in Calcium and Phosphorus ions level was higher or significant in group A than in group B. Higher decrease in Calcium and Phosphorus ions loss post-treatment denotes that Group A with fluoride prevents demineralisation better.

This is an in-vitro study and does not imitate the diverse environment present in the oral cavity. Various factors which may affect dental caries development, such as the dynamics of the caries process, saliva, antimicrobial proteins and enzymes, are challenging to achieve in an in-vitro state. Therefore, further in vivo studies are needed to substantiate the effect of the remineralising agents used.

\section{Conclusion}

The teeth samples applied by the CPP-ACP with Fluoride exhibited better remineralisation than the teeth applied with S-PRG Fillers.

There was reduced calcium and phosphorus ions loss after remineralisation in Group A by indicating a better remineralising potential than Group B.
Conflicts of interest: Authors declared no conflicts of interest.

\section{Financial support: None}

\section{References}

1. Gamea SA, Etman WM, Abdalla AI, Saudi HI. Invitro quantitative evaluation of the effectiveness of different techniques on the of incipient enamel demineralization. Tanta Dent J. 2017;14(1):30-39. https://doi.org/10.4103/tdj.tdj_64_16

2. Cochrane NJ, Cai F, Huq NL, Burrow MF, Reynolds EC. New approaches to enhanced remineralization of tooth enamel. J Dent Res. 2010;89(11):1187-97. https://doi.org/10.1177/0022034510376046

3. Subramaniam P, Babu KG, Lakhotia D. Evaluation of penetration depth of a commercially available resin infiltrate into artificially created enamel lesions: An in vitro study. J Conserv Dent. 2014;17(2):146-149. https://doi.org/10.4103/0972-0707.128054

4. Pitts NB, Zero D. White paper on dental caries prevention and management. FDI World Dental Federation. 2016:3-9.

5. Chaudhary I, Tripathi AM, Yadav G, Saha S. Effect of Casein Phosphopeptide-amorphous Calcium Phosphate and Calcium Sodium Phosphosilicate on Artificial Carious Lesions: An in vitro Study. Int J Clin Pediatr Dent. 2017;10(3):261-266.

https://doi.org/10.5005/jp-journals-10005-1447

6. Shivanna V, Shivakumar B. Novel treatment of white spot lesions: A report of two cases. J Conserv Dent. 2011;14(4):423-26.

https://doi.org/10.4103/0972-0707.87217

7. Frencken JE, Peters MC, Manton DJ, Leal SC, Gordan VV, Eden E. Minimal intervention dentistry for managing dental caries-a review: report of a FDI task group. Int Dent J. 2012;62(5):223-43. https:// doi.org/10.1111/idj.12007

8. Babu KG, Subramaniam P, Teleti S. Remineralization potential of varnish containing casein phosphopeptides-amorphous calcium phosphate with fluoride and varnish containing only fluoride: A comparative study. Saudi J Oral Sci. 2018;5(1):35-40. https:// doi.org/10.4103/sjos.SJOralSci 4417

9. Arends J, Ten Cate JM. Tooth enamel remineralization. J Cryst Growth. 1981; 53:135-147. https:// doi.org/10.1016/0022-0248(81)90060-9

10. Almeida MQ, Costa OX, Ferreira JM, Menezes VA, Leal RB, Sampaio FC. Therapeutic potential of Brazilian fluoride varnishes: an in vivo study. Braz Dent J. 2011;22(3):193-7.

https://doi.org/10.1590/S0103-64402011000300003

11. Kariya S, Sato T, Sakaguchi Y, Yoshii E. Fluoride effect on acid resistance capacity of CPP-ACP containing material. General Session of the IADR, Honolulu, Hawaii. 2004. 
12. Wakamatsu N, Ogika M, Okano T, Murabayashi C, Kondo T, Iinuma M. Effect of tooth surface coating material containing S-PRG filler on white spot lesions of young permanent teeth. Pediatr Dent J. 2018;28 (1):40-5. https://doi.org/10.1016/j.pdj.2017.09.001

13. Assiry AA. Evaluation of remineralization potential of casein phospho-peptide with amorphous calcium phosphate fluoride (CPP-ACPF) on demineralised enamel surfaces. Biomed Res. 2019;30(4): 628-32. https://doi.org/10.35841/biomedicalresearch.30-19$\underline{291}$

14. Torres CR, Borges AB, Torres LM, Gomes IS, de Oliveira RS. Effect of caries infiltration technique and fluoride therapy on the colour masking of white spot lesions. J Dent. 2011;39 (3):202-7. https://doi.org/10.1016/j.jdent.2010.12.004

15. Baafif HA, Alibrahim IF, Alotaibi SH, Alharbi HG, Shubaily MN, Elkwatehy WM. The efficacy of resin infiltrant and casein phosphopeptide-amorphous calcium fluoride phosphate in treatment of white spot lesions (comparative study). J Int Soc Prevent Communit Dent. 2020;10(4):438-44. https://doi.org/10.4103/jispcd.JISPCD $483 \quad 19$

16. Shiiya T, Kataoka A, Fujino F, Tomiyama K, Iizuka J, Hasegawa H, Kuramochi E, Ohashi K, Nihei T, Mukai Y. Anti-demineralization effect of novel SPRG filler containing varnishes on dentin. Dent Mater. 2015(31):e20.

https://doi.org/10.1016/j.dental.2015.08.047 